\title{
Costs of bariatric surgery in a teaching Hospital and the financing provided by the Public Unified Health System ${ }^{1}$
}

\author{
Os custos da cirurgia bariátrica em Hospital Universitário e a remuneração do Sistema Único de \\ Saúde
}

\author{
Wilson Salgado Júnior', Karoline Calfa Pitanga ${ }^{\mathrm{II}}$, José Sebastião dos Santos ${ }^{\mathrm{III}}$, Ajith Kumar Sankarankutty ${ }^{\mathrm{I}}$, Orlando de Castro \\ e Silva Jriv, Reginaldo Ceneviva ${ }^{\mathrm{V}}$
}

\begin{abstract}
${ }^{\text {I }} \mathrm{PhD}$, Division of Digestive Surgery, Department of Surgery and Anatomy, University Hospital, FMRP-USP, Ribeirão Preto, Brazil.

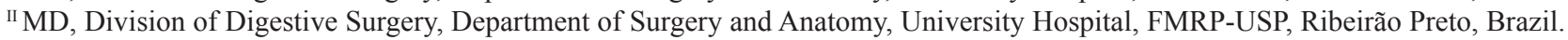

III Associate Professor, Division of Digestive Surgery, Department of Surgery and Anatomy, University Hospital, FMRP-USP, Ribeirão Preto, Brazil.

${ }^{\text {IV }}$ Chairman and Head of the Division of Digestive Surgery, Department of Surgery and Anatomy, University Hospital, FMRP-USP, Ribeirão Preto, Brazil.
\end{abstract}

${ }^{\mathrm{v}}$ Full Professor, Division of Digestive Surgery, Department of Surgery and Anatomy, University Hospital, FMRP-USP, Ribeirão Preto, Brazil.

\begin{abstract}
Purpose: Analyze the effect of some measures on the costs of bariatric surgery, adopting as reference the remuneration of the procedure provided by the Unified Health System (SUS). Methods: A retrospective evaluation conducted in the Costs Section of the University Hospital of Ribeirão Preto, of the costs involved in the perioperative period for patients submitted to bariatric surgery from 2004 to 2007. Changes in the routines and protocols of the service aiming at the reduction of these costs during the study period were also analyzed. Results: Nine patients in 2004 and seven in 2007 submitted to conventional vertical banded "Roux-en-Y" gastric bypass were studied. All patients presented good postoperative evolution. The average cost with these patients was R\$ 6,845.17 in 2004 . Even though an effort was made to contain expenditures, the cost in 2007 was of $\mathrm{R} \$ 7,525.64$ because of the increase in the price of materials and medicines. The Government remuneration of the procedure in the two years was R\$ 3,259.72. Conclusion: Despite the adoption of diverse measures to reduce the expenditures of bariatric surgery, in fact there was an increase in the costs, a fact supporting the necessity of permanent evaluation of the financing of public health.
\end{abstract}

Key words: Costs and Cost Analysis. Bariatric Surgery. Single Health System. Financing, Health.

\section{RESUMO}

Objetivo: Avaliar os efeitos de algumas providências para reduzir os custos da cirurgia bariátrica, adotando como referência a remuneração do procedimento pelo Sistema Único de Saúde. Métodos: Análise retrospectiva, junto a Seção de Custos do Hospital das Clínicas de Ribeirão Preto, dos gastos com os pacientes submetidos a cirurgia bariátrica nos anos de 2004 e em 2007, após a adoção de rotinas e protocolos, no intervalo destes anos, na perspectiva de obter redução das despesas. Resultados: Nove pacientes no ano de 2004 e sete no ano de 2007, submetidos à derivação gástrica em "Y de Roux" com anel por via convencional, foram estudados. Todos pacientes apresentaram boa evolução pós- operatória. O custo médio com estes pacientes no ano de 2004 foi de R\$ 6.845, 17. Apesar do esforço na contenção de despesas, o custo no ano de 2007 foi de R \$ 7.525,64, por conta do aumento do preço de materiais e medicamentos. A remuneração do procedimento pelo SUS nos dois anos foi de R\$ 3.259,72. Conclusão: Apesar da adoção de diversas medidas para reduzir as despesas da cirurgia bariátrica, houve aumento dos custos, o que reforça a necessidade de avaliação permanente do financiamento da prestação de serviço para o SUS pelos três entes da federação.

Descritores: Custos e Análise de Custo. Cirurgia Bariátrica. Sistema Único de Saúde. Financiamento em Saúde.

${ }^{1}$ Research performed at Division of Digestive Surgery, Department of Surgery and Anatomy, University Hospital, School of Medicine of Ribeirão Preto (FMRP), São Paulo University (USP), Brazil.

\section{Introduction}

Morbid obesity is associated with diabetes mellitus, arterial hypertension and sleep apnea, among other co-morbidities ${ }^{1}$. It is also related to important socioeconomic problems that burden the Unified Health System (SUS). Conservative treatments applied in an attempt to obtain a significant and sustained reduction of body mass in this group of patients have proved to be ineffective ${ }^{2}$. Bariatric surgery results in a sustainable loss of body mass, which in most cases is sufficient to cure or improve the above comorbidities $^{3}$.

The cost/benefit ratio of this surgery have been questioned by members of the government and by supplementary health 
managers. However, several studies have demonstrated savings in health costs after bariatric surgery, in addition to increased patient productivity and reduced work absenteeism ${ }^{4-6}$.

In Brazil, this surgical procedure was regulated by SUS to be performed by the public health network by means of Directive GM/MS 628 of April 26, 20017. Up to the first half of 2007, SUS remunerated accredited hospitals with a value of R $\$$ 3,259.72 for the procedure.

A patient who is a candidate for bariatric surgery requires judicious clinical and laboratory assessment with the frequent need for compensation of co-morbidities during the preoperative period, as well as special care after surgery, with a consequent increase in the cost of treatment.

After an analysis of the costs of this surgery in our service in 2004 and the presentation of the data obtained at the Specialty Congress, measures were taken in order to reduce expenses.

Thus, the objective of the present study was to compare the perioperative costs of bariatric surgery at the University Hospital of the Faculty of Medicine of Ribeirão Preto-USP in 2004 and 2007, in view of the efforts for the containment of expenses and also to compare these costs to the value remunerated by the federal manager of SUS for this procedure.

\section{Methods}

A retrospective analysis was carried out to record the direct and indirect costs of bariatric surgery, excluding expenses with medical personnel, performed in 2004 and 2007 at the University Hospital of the Faculty of Medicine of Ribeirão Preto-USP. The data were obtained from the Technical Advisory
Office of the Hospital. This is a tertiary care reference University Hospital affiliated to the University of São Paulo. The study was conducted on a sample of patients who did not present any hospital complication that might require increased expenditures.

All patients were submitted to ring Roux-en-Y gastric bypass by the standard route, also known as Capella surgery.

The study was conducted in the years 2004 and 2007 before and after a revision of the work protocols made between these years. The measures adopted in the revision of the protocol aimed at containing expenses by reducing the duration of hospitalization and by revising the surgical strategy.

The costs of surgical treatment of morbid obesity during these years, excluding expenditures with the medical team, were compared to the value remunerated by SUS for this type of surgery.

\section{Results}

In 2004, nine patients with a mean age of 42 years (range: $28-53$ years), with a mean weight of $131 \mathrm{~kg}$ (range: $111-162 \mathrm{~kg}$ ) and a mean body mass index of $52 \mathrm{~kg} / \mathrm{m}^{2}$ (range: $44-57 \mathrm{~kg} / \mathrm{m}^{2}$ ) were evaluated. The patients were admitted six days before the surgical procedures for some texts and for multiprofessional assessment. Stomach and jejunum section and suture were performed using four staples with a linear cutting device. The mean surgical time for these patients was 4 hours and 31 minutes and the duration of the postoperative hospital stay was seven days, up to the time of drain removal. The mean total cost for the patients during hospitalization was $\mathrm{R} \$ 6,845.17$ and the remuneration by the federal manager was $\mathrm{R} \$ 3,259.72$ (Table 1).

TABLE 1 - Perioperative costs of bariatric surgery at the University Hospital, Faculty of Medicine of Ribeirão Preto-USP in 2004. Values are reported in reais

\begin{tabular}{|c|c|c|c|c|c|c|}
\hline Patients & Hospitalization $^{1}$ & $\begin{array}{l}\text { Surgery } \\
\text { Center }^{2}\end{array}$ & Exams $^{3}$ & Medications $^{4}$ & Materials $^{5}$ & Total \\
\hline 1 & 2937.93 & 1936.35 & 145 & 430 & 1542.7 & 6991.98 \\
\hline 2 & 2729.13 & 1898.87 & 205.03 & 462.38 & 1542.7 & 6838.11 \\
\hline 3 & 2951.94 & 1682.07 & 175.31 & 506.41 & 1622.7 & 6938.43 \\
\hline 4 & 3148.83 & 1823.93 & 332.48 & 191.41 & 1542.7 & 7039.35 \\
\hline 5 & 2726.97 & 1915.04 & 180 & 480 & 1542.7 & 6844.71 \\
\hline 6 & 2729.13 & 2065.57 & 210.32 & 320 & 1542.7 & 6867.72 \\
\hline 7 & 2937.93 & 2217.17 & 200 & 350 & 1542.7 & 7247.8 \\
\hline 8 & 2309.43 & 2065.6 & 185 & 450 & 1542.7 & 6552.73 \\
\hline 9 & 2522.52 & 1648 & 180 & 392.52 & 1542.7 & 6285.74 \\
\hline Mean & 2777.09 & 1916.956 & 201.46 & 398.08 & 1551.58 & 6845.17 \\
\hline SDd & 252.76 & 184.1124 & 52.82 & 98.39 & 26.66 & 280.48 \\
\hline
\end{tabular}

1- Hospitalization costs excluding the costs of exams and medications

2- Surgery center costs including anesthesia (except the costs of staplers and catheters)

3- Pre- and postoperative laboratory and imaging exams

4- Medications used before and after surgery, excluding anesthetics

5- Staplers and catheters 
After revision of the protocol, in 2007 the time of preoperative hospitalization was reduced to 4 days and the surgical time was reduced to 3 hours and 20 minutes. With small changes in the surgical strategy, the procedure started to be performed with only 3 staples. Finally, there was a reduction in postoperative hospitalization, with the patients being discharged on the fourth day, while still carrying the abdominal drain.
In 2007 , seven patients with a mean age of 40 years, with a mean weight of $137 \mathrm{~kg}$ and a mean BMI of $51.7 \mathrm{~kg} / \mathrm{m}^{2}$, were evaluated. Despite the measures implemented, the mean cost was $\mathrm{R} \$ 7,525.64$, i.e., $\mathrm{R} \$ 680.47$ more than in 2004 . This increase was due to the elevation of the costs of anesthetics and consumables within the surgery center. The remuneration for the procedure provided by the federal manager was the same as for the year of 2004 (Table 2).

TABLE 2 - Perioperative costs of bariatric surgery at the University Hospital, Faculty of Medicine of Ribeirão Preto-USP in 2007. Values are reported in reais

\begin{tabular}{|c|c|c|c|c|c|c|}
\hline Patients & Hospitalization ${ }^{1}$ & $\begin{array}{l}\text { Surgery } \\
\text { Center }^{2}\end{array}$ & Exams $^{3}$ & Medications ${ }^{4}$ & Materials $^{5}$ & Total \\
\hline 1 & 2501.15 & 2694.18 & 374.66 & 307.87 & 1977.01 & 7855.05 \\
\hline 2 & 1772.89 & 2773.67 & 153.77 & 115.76 & 1857.53 & 6663.82 \\
\hline 3 & 1813.01 & 3012.48 & 87.32 & 224 & 2223.09 & 7350.2 \\
\hline 4 & 1972.75 & 3380.56 & 15 & 273.45 & 2175.49 & 7807.51 \\
\hline 5 & 2020.98 & 2886.91 & 288.67 & 339.69 & 1868.18 & 7394.64 \\
\hline 6 & 2041.04 & 3146.76 & 254.72 & 395.49 & 1926.46 & 7764.7 \\
\hline 7 & 2020.98 & 3408.11 & 299.62 & 237.72 & 1886.91 & 7843.6 \\
\hline Mean & 2020.4 & 3043.239 & 210.54 & 270.57 & 1987.81 & 7525.646 \\
\hline SD & 237.38 & 282.1133 & 128.82 & 90.37 & 150.5135 & 435.2937 \\
\hline
\end{tabular}

1- Hospitalization costs excluding the costs of exams and medications

2- Surgery center costs including anesthesia (except the costs of staplers and catheters)

3- Pre- and postoperative laboratory and imaging exams

4- Medications used before and after surgery, excluding anesthetics

5- Staplers and catheters

\section{Discussion}

Clinically significant obesity has become a global epidemic with great socioeconomic implications for the health system. The expenditures with obese patients tend to continue to increase. In a system in which the resources allocated to health are increasingly limited, the rational use of financial resources is essential in order to maintain the quality of patient care.

There is no question about the importance of public financing of health services in Brazil, where more than $30 \%$ of the population lives in a state of poverty. In August 2000, Constitutional Amendment 29 was approved, which allotted 
minimum percentages of the revenue of the three spheres of government to the free provision of goods and health services to the population. With this amendment, the minimum amount to be applied to public health actions and services was $12 \%$ of the revenues of the states and $15 \%$ of the revenues of the municipalities ${ }^{8}$.

Although some increase in nominal values was also observed in federal allotments, there was a substantial reduction of the percentage of participation of health in the current revenues of the Union. In 1994, the Federal participation was $60.7 \%$ of the total revenue, with this value being reduced to $50.1 \%$ in $2004^{8}$.

In 2004 The Health and Education Ministries published a series of directives (Interministerial directives $\mathrm{n}^{\circ} 1,000,1,005,1,006$ and 1,007 of 2004) which changed the form of certification of teaching hospitals and of the financing of these establishments, reintroducing the modality of global budgeting. The basis for the calculation of the fixed monthly remuneration was defined as the historical series of the services provided, with the addition of FIDEPS values (Factor of Incentive of the Development of Health Teaching and Research), of new incentives and of the impact of future adjustments of the remuneration values for ambulatory and hospital procedures, among others (Interministerial Directive 1.006 of May 2004, art. $4^{\circ}$ ).

However, this is not the reality at other hospitals attending SUS patients. Managers of philanthropic institutions estimated that the values remunerated by SUS in 2005 represented about $30 \%$ of their crude income. Nevertheless, other forms of state subsidies (forfeited charges and taxes) and diversification including the creation of their own health plans - permitted these hospitals to overcome the situation and even to grow. Many other profit private hospitals stopped their agreements with SUS and still others closed due to the increase of the "mean value" of hospitalization 9 .

Within this context, the costs of bariatric surgery in our service exceeded the values paid by the Hospital Information System Table of SUS (SIH/SUS) for the procedure. There are no indexed publications dealing with the costs of bariatric surgery in Brazil.

In the United States, the estimate is that $7 \%$ of all health costs involve the treatment of obesity and its associated diseases ${ }^{4}$. Similarly, the cost of bariatric surgery is also elevated.

The expenses involved in bariatric surgery vary widely among institutions depending on the profile of the population attended, on the routines of the services and on capital management. They also vary according to the form of health financing. Paradoxically, Angus et al. ${ }^{10}$ demonstrated that the hospital costs of bariatric surgery were higher (US\$ 11,773.00) in the public health system (Medicare and Medicaid) compared to private care (US\$4,435.00). Several other authors have reported widely varying costs ranging from US\$ 7,800.00 to US\$20,500.004,11-14.

The changes in the routines of our service were implemented without any reduction of the quality of care. Although the costs increased between the two periods studied, it is clear that if these measures had not been taken, the cost of bariatric surgery at out institution would have been even higher.

Obviously technological advances involve financial consequences. However, in many cases there a disproportionate inflation of the prices of materials and medications.
In any case, the most significant evidence obtained in the present study was that, with some exceptions such as transplants, high-complexity treatment in the public assistance network cannot count exclusively on federal funding. Other sources of funding must be guaranteed so that other hospitals may perform these procedures.

According to the Government Directive MS/GM n ${ }^{\circ} 493$, of August 31, 2007 ${ }^{15}$, the remuneration values proposed for hospitals accredited to perform bariatric surgery were increased to $\mathrm{R} \$ 4,614.82$ for the type of surgery performed in our service, an amount that, in any case, is still insufficient.

We conclude that, despite the efforts to decrease hospital costs such as reduction of pre- and postoperative hospital stay, there was no reduction in the total costs for the patients evaluated. During the study period there was no adjustment of the remuneration provided by SUS for this procedure, a fact that renders it unfeasible to perform this surgery in hospital depending only on the remuneration of the SIH/SUS Table.

\section{Conclusion}

Despite the adoption of diverse measures to reduce the expenditures of bariatric surgery, there was an increase in the costs, a fact supporting the necessity of permanent evaluation of the financing of public health.

\section{References}

1. Mokdad AH, Ford ES, Bowman BA, Dietz WH, Vinicor F, Bales VS, Marks JS. Prevalence of obesity, diabetes and obesity-related health risk factors. JAMA. 2003;289(1):76-9.

2. Methods for voluntary weight loss and control. A National Institute of Health Technology Assessment Conference (Summarized by Mason EE). Obes Surg. 1992;2:275-6.

3. Dhabuwala A, Caunan RJ, Stubbs RS. Improvements in co-morbidities following weight loss from gastric bypass surgery. Obes Surg. 2000;10:428-35. 4. Gallagher SF, Banasiak M, Gonzalvo JP, Paoli DP, Allwood J, Morris D, Murr MM, Shapiro DH. The impact of bariatric surgery on the Veterans Administration healthcare system: a cost analysis. Obes Surg. 2003;13(2):245-8.

5. Deitel M. Bariatric surgery is a cost-saving for Healthcare System. Obes Surg. 2005;15:301-3.

6. Monk JS, Nagib ND, Stehr W. Pharmaceutical savings after gastric bypass surgery. Obes Surg. 2004;13:13-5.

7. Portaria MS/GM n ${ }^{\circ} 628$, de 26 de abril de 2001. Diário Oficial da União; Poder Executivo, Brasília, DF, 27 de abril de 2001. Seção I, p.77-9.

8. Carvalho DMT. Financiamento da assistência médico-hospitalar no Brasil. Ciênc Saúde Coletiva 2007;12(4):879-92.

9. Ronsini MJ. Santas Casas de Misericórdia... Você precisa saber mais sobre elas. Disponível em: http://www.cmb.org.br/informativos.htm [acesso 2006 Jun].

10. Angus LD, Cottam DR, Gorecki PJ, Mourello R, Ortega RE, Adamski J. DRG, costs and reimbursement following Roux-en-Y gastric bypass: an economic appraisal. Obes Surg. 2003;13(4):591-5.

11. Livingston EH. Hospital costs associated with bariatric procedures in the United States. Am J Surg. 2005;190:816-20.

12. Nguyen NT, Goldman C, Rosenquist CJ, Arango A, Cole CJ, Lee SJ, Wolfe BM. Laparoscopic versus open gastric bypass: a randomized study of outcomes, quality of life and costs. Ann Surg. 2001;234:279-89.

13. Craig BM, Tseng DS. Cost effectiveness of gastric bypass for severe obesity. Am J Med. 2002;113:491-8. 
14. DeMaria EJ, Schweitzer MA, Kellum JM, Meador J, Wolfe L, Sugerman HJ. Hand assisted laparoscopic gastric bypass does not improve outcome and increases costs when compared to open gastric bypass for the surgical treatment of obesity. Surg Endosc. 2002;16:1452-5.
15. Portaria MS/GM n ${ }^{\circ} 493$, de 31 de agosto de 2007. Diário Oficial da União; Poder Executivo, Brasília, DF, 5 de setembro de 2007. Seção I, p.36-9.

Conflict of interest: none

Financial source: none

\section{Correspondence:}

Wilson Salgado Júnior

R. Antônio Chiericato, 760

14096-510 Ribeirão Preto - SP Brazil

Phone: (55 16)3618-2676 / 9214-5176

wsalgado@fmrp.usp.br

Received: September 18, 2009

Review: November 19, 2009

Accepted: December 15, 2009

\section{How to cite this article}

Salgado Júnior W, Pitanga KC, Santos JS, Sankarankutty AK, Castro e Silva Jr O, Ceneviva R. Costs of bariatric surgery in a teaching Hospital and the financing provided by the Public Unified Health System. Acta Cir Bras. [serial on the Internet] 2010 Mar-Apr;25(2). Available from URL: http://www.scielo.br/acb 